\title{
HEMIEPIPHYSIODESIS USING EIGHT-PLATE VERSUS BLOUNT STAPLE TO CORRECT GENU VALGUM AND GENU VARUM
}

\section{HEMIEPIFISIODESE COM PLACA EM OITO VERSUS GRAMPO DE BLOUNT PARA CORREÇÃO DO GENO VALGO E GENO VARO}

\author{
Natasha Vogel Majewski Rodrigues ${ }^{1}$ (1), Roberto Guarniero ${ }^{1}$ (i), Paulo José Fortes Villas Boas ${ }^{2}$ (i), \\ BRUNo RodRIGUeS DE MIRANDA ${ }^{3}$ (i), NeI BOtTER MONTENEGRO ${ }^{1}$ (i) \\ 1 Universidade de São Paulo, Medical School, Institute of Orthopedics and Traumatology, Hospital das Clínicas, São Paulo, SP, Brazil. \\ 2 Universidade Estadual Paulista, Medical School, Botucatu, SP, Brazil. \\ ${ }^{3}$ Faculdade de Medicina do ABC, Santo André, SP, Brazil.
}

\section{ABSTRACT}

Objective: Our objective is to evaluate whether the use of guided growth with eight-plates is more effective than the use of Blount staples for the correction of the idiopathic genu varum or idiopathic genu valgum. Methods: A systematic review (SR) was carried out according to the appropriate methodology for randomized clinical trials (RCTs). We searched seven databases through a previously defined methodology, and we included RCTs, regardless of language, period of publication and status of publication. Results:Resulted in 6830 articles retrieved. Of theses, we identified 14 potential eligible studies. but just one RCT was included for the SR. The included RCT compares the eight-plate and the Blount staple and showed no statistically significant difference for the outcomes of time to correct the deformity, postoperative pain after 24 hours and postoperative pain after 72 hours. The study is of low or very low level of evidence to determine the most effective technique. We didn't find a RCT that compared the correction of the genu varum..Conclusion: Good quality randomized clinical trials comparing Blount staples versus eight-plaque must be performed to determine which technique is superior for coronal plane corrections. Level of Evidence I, Systematic review of Level RCTs.

\section{RESUMO}

Objetivo: Avaliar se o uso do crescimento guiado com placas em oito é mais eficaz que os grampos de Blount na correção do geno varo idiopático ou geno valgo idiopático. Métodos: Foi realizada uma revisão sistemática (RS), de acordo com a metodologia apropriada para busca de ensaios clínicos randomizados (ECR). Pesquisamos em sete bancos de dados por meio de uma metodologia definida anteriormente e incluímos ECR, independentemente do idioma, período ou status da publicação. Resultados: Foram recuperados 6830 artigos. Destes, 14 estudos possivelmente elegíveis foram encontrados, mas apenas um ECR foi incluído para a RS. O ECR incluído compara placas em oito e grampos de Blount, não mostrando diferença estatisticamente significante para os resultados de tempo na correção da deformidade, dor pós-operatória após 24 horas e dor pós-operatória após 72 horas. O estudo é de nível baixo ou muito baixo de evidência para determinar a técnica mais eficaz. Não encontramos um ECR que comparasse a correção do geno varo. Conclusão: Ensaios clínicos randomizados de boa qualidade comparando grampos de Blount com oito placas devem ser realizados para determinar qual técnica é superior para correções do plano coronal. Nível de Evidência I, Revisão sistemática de ECRC.

Keywords: Child. Adolescent. Genu Varum. Genu Valgum.

Descritores: Criança. Adolescente. Genu Varum. Genu Valgo.

Citation: Rodrigues NVM, Guarniero R, Villas Boas PJF, Miranda BR, Montenegro NB. Hemiepiphysiodesis using eight-plate versus Blount staple to correct genu valgum and genu varum. Acta Ortop Bras [online]. 2020;28(4):195-8. Available from URL: http://www.scielo.br/aob.

\section{INTRODUCTION}

Frequent complaint at orthopedic departments, ${ }^{1}$ genu varum and genu valgum are asymptomatic coronal deformities physiologically present during the child's growth. ${ }^{1}$ If pathological, they need correction to reduce psychosocial impact caused by symptoms that may vary from aesthetic discomfort to changes in gait patterns which may cause difficulty running, knee pain, poor alignment, and patellar or ligament instability. ${ }^{2}$ In the long term, this clinical picture may result in early joint degeneration, especially in genu varum deformities. ${ }^{3}$

The most frequent treatment was osteotomy. In 1933, Phemister was first described the hemiepiphysiodesis surgical procedure: ${ }^{4}$ a surgery performed at the physeal level that stops growth in the region, which demands a precise timing calculation, as it is non-reversible. In 1945,

All authors declare no potential conflict of interest related to this article.

The study was conducted at Universidade de São Paulo, Medical School, Institute of Orthopedics and Traumatology, Hospital das Clínicas.

Correspondence: Natasha Vogel Majewski Rodrigues. Rua Ovídio Pires de Campos, 333, São Paulo, SP, Brazil, 05403010. natashavogel@hotmail.com

Article received on 01/23/2020, approved on 02/10/2020. 
Haas ${ }^{5}$ proposed slowing physeal growth with metal wires that, after being broken, would allow its growth to resume. Encouraged by Haas' studies, ${ }^{5}$ Blount et al. ${ }^{6}$ and Blount ${ }^{7}$ described using staples for temporary restriction of longitudinal growth in children's physis, which forwent precise timing calculations before procedure.

Over time, less invasive surgical procedures, performed in shorter time and with lower complication rates, were created for patients with immature skeleton. The "tension band" by plate and screws, described by Peter Stevens in 2006, is currently the most used method. ${ }^{8}$ Some authors report lower complication and faster correction rates, ${ }^{2,9}$ whereas others highlight its high cost, which can be up to six times higher than staples. ${ }^{10,11}$ Both procedures - the one by Blount et al., ${ }^{6}$ Blount $^{7}$ and the one by Stevens et al. ${ }^{9}$ - are considered temporary methods that gradually correct knee angular deformities.

Although research show that both procedures effectively temporarily stop limb growth, it does not indicate which would be the preferred method. Some authors state that the eight-plate better compress the bone and the epiphyseal cartilage - which avoids extrusion in small children - and has a lower effect on the longitudinal growth of the bone. Others prefer using staples in patients without much remaining growth, as it speeds. ${ }^{12}$

This review aims to evaluate the efficacy of guided growth with eightplates compared with Blount staples to correct idiopathic genu varum or genu valgum. Primary outcomes are improvement in quality of life; pain score using visual analog scale (VAS) or other knee related symptoms; improvement in limb alignment and function; and adverse events.

\section{MATERIALS AND METHODS}

\section{Search strategy}

We followed Cochrane guidelines, especially PRISMA (Preferred Reporting Items for Systematic Reviews and Meta-Analyses). ${ }^{13}$ We searched the Cochrane Central Register of Controlled Trials (CENTRAL), MEDLINE (PubMed), EMBASE (OVID), LILACS (Latin American and Caribbean Health Sciences Literature), Web of Science, Scopus, and World Health Organization (WHO) databases for relevant studies until January 27, 2019. All relevant studies were identified, regardless of period, publication status and language. To guarantee all relevant study was included, we used specific search filters, such as Cochrane Highly Sensitive Search Strategies (HSSS).

\section{Study selection}

Retrieved studies were cataloged using EndNote X9.2. Duplicated studies were evaluated using online platform Rayyan QCRI. Two reviewers independently and separately analyzed and reviewed all study titles, abstracts, and keywords. Disagreements were solved through discussion and, whenever necessary, a third reviewer was consulted. We included all randomized controlled trials (RCT) that compared the use of eight-plate with Blount staples to treat idiopathic genu valgum and genu varum in children of both genders, aged 2-18 years old with open physis. For the purpose of this review, we excluded studies using other methods or techniques.

\section{Types of outcome measures}

Primary outcomes were improvement in quality of life; postoperative pain score using VAS or other knee related symptoms; improvement in limb alignment and function; and adverse events (material failure, reoperation rate, and superficial or deep infection).

\section{Risk of bias assessment in included studies}

Two reviewers (NVMR, BRM) independently analyzed the risk of bias in the included study using the Cochrane Collaboration's Risk of Bias tool, ${ }^{14}$ assessing: random sequence generation; allocation concealment; blinding; similarity of baseline outcome measurements; similarity of baseline characteristics; blinding of outcome assessment; incomplete reporting; and other sources. Each of these criteria was explicitly judged by applying low risk of bias, high risk of bias, or unclear risk of bias (lack of precise information or uncertainty over potential bias).

\section{Study quality assessment}

We evaluated the overall strength of evidence to each result of the included study using GRADE (Grading of Recommendations Assessment, Development and Evaluation), ${ }^{15}$ analyzing: inconsistency, imprecision, indirectness, risk of bias, and potential publication bias. When appropriated, the level of evidence was lowered by one, two, or three levels - from "high quality" to "moderate quality", "low quality", or "very low quality".

\section{RESULTS}

\section{Study characteristics}

We retrieved and cataloged 6830 papers. Of these, 1956 were duplicates, which left us with 4974 papers. After reading all titles and abstracts, we selected 14 potentially eligible studies, which were retrieved and read. Of these, we included only one RCT. ${ }^{16}$ The flow diagram of this systematic review is depicted by Figure 1 , as recommended by PRISMA. ${ }^{13}$

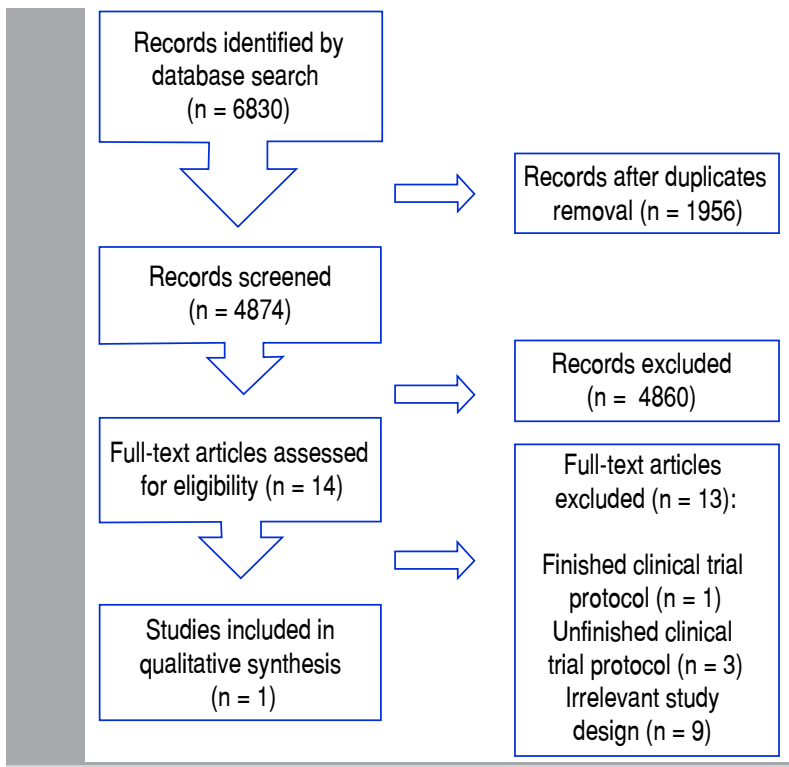

Figure 1. PRISMA flow diagram of the systematic review.

The study included compared both methods relevant in this systematic review: eight-plate and Blount staples. The study evaluated outcomes, total time for correction, and postoperative pain score using visual analog scale (VAS). It included 26 children aged 8-15 with estimated remaining growth of at least 6 months and bilateral genu valgum of at least $7 \mathrm{~cm}$ of intermalleolar distance. The study provided outcome data on treatment time of 20 randomized children: 11 boys and 9 girls. Postoperative pain score was evaluated in only 18 children.

Outcomes: total time for correction and percentage of patients with other interventions

The study analyzed correction time in days, counting from the surgery date until implants removal. The criterion for other interventions was intermalleolar distance after implant removal. Treatment time did not vary significantly between groups (340 \pm 54 days versus 349 days \pm 86 days, $95 \% \mathrm{Cl}$, average difference of 9 days; $\mathrm{P}$ 0.78) (Figure 2). 


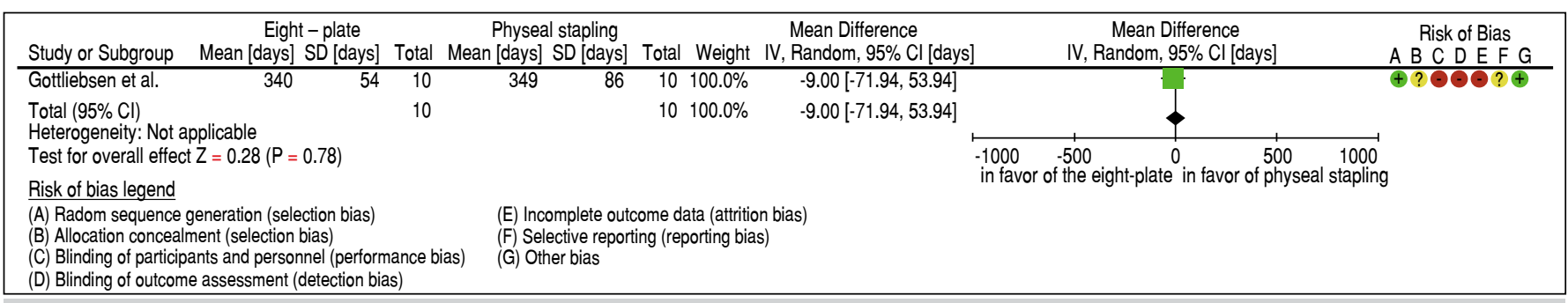

Figure 2. Comparison between two techniques: eight-plate and Blount staples.

Postoperative pain score - 24 hours, VAS (second outcome) The study used visual analog scale (VAS) validated for children after lower-extremity surgery twice a day for 72 hours (charts were answered by parents). All patients received standardized postoperative pain treatment. We evaluated pain outcome 24 and 72 hours after surgery. Only 18 out of 20 children were evaluated by VAS, which resulted in no significant statistic difference between both groups ( $p=0.83$ ). In the eight-plate group, the average was 0.56 (minimum value 0.17; maximum value 0.78). In the Blount staples group, the average was 0.54 (minimum value 0.13 ; maximum value 0.82 ). However, the sample is underestimated and authors do not describe how patients were divided. Data on variability were not published (standard deviation or confidence interval).

Postoperative pain score - 72 hours, VAS (second outcome) Only 18 out of 20 children were evaluated using VAS, which resulted in no significant statistic difference between both groups $(p=0.66)$. In the eight-plate group, the average was 0.25 (minimum value 0 ; maximum value 0.66 ). In the Blount staples group, the average was 0.30 (minimum value 0 ; maximum value 0.66 ). This sample is also underestimated, with no description of how patients were divided. Data on variability were not published (standard deviation or confidence interval).

\section{Adverse events}

The study did not observe adverse events such as implant failure, infection or physeal injury.

Risk of bias assessment

Table 1 describes the risk of bias assessment and Figure 3 the authors' judgement.

\begin{tabular}{c|c|c}
\multicolumn{1}{c|}{ Bable 1. Risk of bias. } & $\begin{array}{c}\text { Authors' } \\
\text { judgement }\end{array}$ & Support for judgement \\
\hline $\begin{array}{c}\text { Random sequence } \\
\text { generation (selection bias) }\end{array}$ & Low risk & $\begin{array}{c}\text { Randomization done by a third } \\
\text { unaffiliated party, who mixed and } \\
\text { randomly numbered the envelopes. }\end{array}$ \\
\hline $\begin{array}{c}\text { Allocation concealment } \\
\text { (selection bias) }\end{array}$ & Unclear risk & $\begin{array}{c}\text { Envelopes were mixed and randomly } \\
\text { numbered for allocation concealment, } \\
\text { but the study does not specify if the } \\
\text { envelopes were opaque or sealed. }\end{array}$ \\
\hline $\begin{array}{c}\text { Blinding of participants and } \\
\text { personnel (performance bias) }\end{array}$ & High risk & $\begin{array}{c}\text { Participants and surgeons } \\
\text { were not blinded. }\end{array}$ \\
\hline $\begin{array}{c}\text { Blinding of outcome } \\
\text { assessment (detection bias) }\end{array}$ & High risk & $\begin{array}{c}\text { Outcome assessments } \\
\text { were not blinded. }\end{array}$ \\
\hline $\begin{array}{c}\text { Incomplete outcome data } \\
\text { addressed (attrition bias) }\end{array}$ & High risk & $\begin{array}{c}\text { Excluded participants did not alter } \\
\text { proportion between groups, but there } \\
\text { were not enough participants in } \\
\text { each group to reach the minimum. }\end{array}$ \\
\hline $\begin{array}{c}\text { Selective reporting } \\
\text { (reporting bias) }\end{array}$ & Unclear risk & $\begin{array}{c}\text { Study protocol was published and all } \\
\text { outcomes are described in this review. } \\
\text { It lacks enough data to interpret VAS. }\end{array}$ \\
\hline $\begin{array}{c}\text { Other potential } \\
\text { sources of bias }\end{array}$ & Low risk & $\begin{array}{l}\text { The study was not financed by private } \\
\text { companies during or after completion. }\end{array}$ \\
\hline
\end{tabular}

\section{Quality of evidence}

For treatment outcome, we downgraded the level of evidence by one for risk of bias due to absence of blinding, incomplete follow-up and lack of analysis of intention-to-treat. We also downgraded the level of evidence to imprecise because both groups lacked the estimated sample size. ${ }^{7}$

For pain outcome, we lowered the level of evidence by two due to absence of blinding, incomplete follow-up, lack of analysis of intention-to-treat and selective reporting, as only 18 out of 20 children were evaluated. Although lacking statistic difference, the authors do not describe how patients were divided into groups. We also downgraded the level of evidence to imprecise because the study was completed using a smaller sample size. We concluded that the evidence is of low quality, meaning that confidence in effect is limited or of very low quality. Therefore, confidence in estimated effects is very limited, with an important level of uncertainty in findings.

\section{Potential revision bias}

We tried to reduce revision bias by comprehensive search for trials and adherence to our protocol (PROSPERO 2018 CRD42018086661). Even with a comprehensible search strategy, with no linguistic limitations, we may have missed some studies after checking the references of relevant papers. We contacted the author of the included study to retrieve unreported data and he provided supplementary information. We also contacted authors of unfinished studies, but received only one answer.

We found no RCT evaluating genu varum correction by eightplate or Blount staples, which limited this review. We also need to address potential publication bias, which threatens the validity of systematic reviews, especially those that include few and small clinical trials (Figure 3 ).

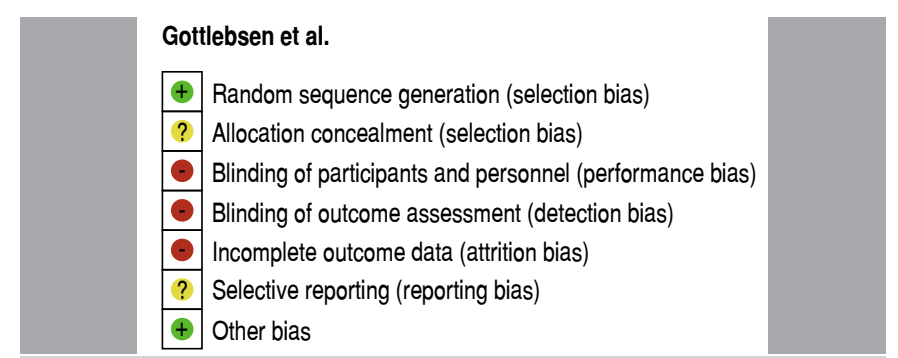

Figure 3. Risk of bias summary: review of authors' judgements about each risk of bias item for the study of Gottliebsen et al. ${ }^{16}$

\section{DISCUSSION}

Although the eight-plate is largely used to correct lower limb deformities, this systematic review shows the literature lacks enough randomized controlled trials with high levels of evidence to help establish the best technique to correct idiopathic genu valgum and genu varum.

Even if our systematic review is similar to some studies ${ }^{12,17-19}$ on the similarities between both techniques, we must address some 
limitations. First, its high risk of performance, detection, and attrition bias. Second, its low level of evidence for treatment time and third, the very low level of evidence for postoperative pain score 24 and 72 hours after surgery. Other studies ${ }^{10,17}$ mention the high costs of the eight-plate; but correction with this method requires less surgical time $^{18}$ and is more surgeon-friendly. Radiation exposure ${ }^{20}$ must also be considered when choosing an implant technique. Lastly, some important outcomes were unevaluated: quality of life; adverse events in all follow-up phases, including after implant removal for a long-term period; return to normal activities; postoperative rehabilitation; knee related symptoms; range of movement; ligament stability; personal satisfaction with physical appearance; surgical time; radiation exposure during surgery; and total costs of each procedure. An important exclusion criterion was the presence of associated deformities, for this might cause result misinterpretation.

\section{CONCLUSION}

More high quality RCTs comparing Blount staples and eight-plates to correct idiopathic genu varum and genu valgum are needed. We found no RCTs comparing both techniques to treat idiopathic genu varum in children. Scientific evidence based on randomized controlled trials is inadequate to decide which method is more efficient to correct idiopathic genu varum and genu valgum in children. More high quality RCTs are needed to help choose the best implant in each case. We suggest that future RCTs follow CONSORT guidelines and report data on outcomes of patients with adverse events.

AUTHORS' CONTRIBUTIONS: Each author contributed individually and significantly to the development of this article. NVMR: study design and planning data collection, bibliographic review, writing of the article, data interpretation, article review and final version approval; RG: article review, final version approval; PJFVB: data interpretation and final version approval; BRM: data interpretation, bibliographic review, article review and final version approval; NBM: article review and final version approval.

\section{REFERENCES}

1. Herring JA. Tachdjian's pediatric orthopaedics. 4th ed. Philadelphia: Saunders Elsevier; 2008

2. Stevens PM. Guided growth for angular correction: a preliminary series using a tension band plate. J Pediatr Orthop. 2007;27(3):253-9.

3. Sharma L, Song J, Dunlop D, Felson D, Lewis CE, Segal N, et al. Varus and valgus alignment and incident and progressive knee osteoarthritis. Ann Rheum Dis. 2010;69(11):1940-5

4. Phemister DB. Operative arrestment of longitudinal growth of bones in the treatment of deformities. J Bone Joint Surg Am. 1933;15(1):1-15.

5. Haas SL. Retardation of bone growth by wire loop. J Bone Joint Surg Am. 1945;27(1):25-36.

6. Blount WP, Clarke GR. Control of bone growth by epiphyseal stapling: a preliminary report. J Bone Joint Surg Am. 1949;31A(3):464-78.

7. Blount WP. A mature look at epiphyseal stapling. Clin Orthop Relat Res. 1971;77:158-63.

8. Stevens PM. Guided growth: 1933 to the present. Strategies Trauma Limb Reconstr. 2006;1(1):29-35.

9. Stevens PM, Klatt JB. Guided growth for pathological physes: radiographic improvement during realignment. J Pediatr Orthop. 2008;28(6):632-9.

10. Burghardt RD, Herzenberg JE, Standard SC, Paley D. Temporary hemiepiphyseal arrest using a screw and plate device to treat knee and ankle deformities in children: a preliminary report. J Child Orthop. 2008;2(3):187-97.

11. Burghardt RD, Herzenberg JE. Temporary hemiepiphysiodesis with the eight-plate for angular deformities: mid-term results. J Orthop Sci. 2010;15(5):699-704

12. Goyeneche RA, Primomo CE, Lambert N, Miscione H. Correction of bone angular deformities: Experimental analysis of staples versus 8-plate. J Pediatr Orthop. 2009;29(7):736-40.
13. Moher D, Liberati A, Tetzlaff J, Altman DG, PRISMA Group. Preferred reporting items for systematic reviews and meta-analyses: the PRISMA Statement. PLoS Med. 2009;6(7):e1000097.

14. Higgins JPT, Green S, editors. Cochrane handbook for systematic reviews of interventions. London: The Cochrane Collaboration; 2011.

15. Guyatt GH, Oxman AD, Vist GE, Kunz R, Falck-Ytter Y, Alonso-Coello P, et al. GRADE: an emerging consensus on rating quality of evidence and strength of recommendations. BMJ. 2008;336(7650):924-6.

16. Gottliebsen M, Rahbek O, Hvid I, Davidsen M, Hellfritzsch MB, Møller-Madsen B. Hemiepiphysiodesis: similar treatment time for tension-band plating and for stapling. Acta Orthop. 2013;84(2):202-6.

17. Wiemann JM 4th, Tryon C, Szalay EA. Physeal stapling versus 8-plate hemiepiphysiodesis for guided correction of angular deformity about the knee. J Pediatr Orthop. 2009;29(5):481-5.

18. Jelinek EM, Bittersohl B, Martiny F, Scharfstädt A, Krauspe R, Westhoff B. The 8-plate versus physeal stapling for temporary hemiepiphyseodesis correcting genu valgum and genu varum: a retrospective analysis of thirty five patients. Int Orthop. 2012;36(3):599-605.

19. Kumar A, Gaba S, Sud A, Mandlecha P, Goel L, Nayak M. Comparative study between staples and eight plate in the management of coronal plane deformities of the knee in skeletally immature children. J Child Orthop. 2016;10(5):429-37

20. Masquijo JJ, Lanfranchi L, Torres-Gomez A, Allende V. Guided growth with the tension band plate construct: a prospective comparison of 2 methods of implant placement. J Pediatr Orthop. 2015;35(3):e20-5. 